\title{
O DESENVOLVIMENTO DE RECURSOS EM REDES INTERORGANIZACIONAIS E O PROCESSO DE INTERNACIONALIZAÇÃO: O CASO WINES OF BRASIL
}

\section{THE DEVELOPMENTOF RESOURCES ININTERORGANIZATIONALNETWORKSAND THEINTERNATIONALIZATION PROCESS: THE CASE WINES OF BRASIL}

\section{DESARROLLO DE RECURSOS Y PROCESO INTERORGANIZACIONAL REDES INTERNACIONALIZACIÓN: EL CASO DE LOS VINOS DEL BRASIL}

\author{
Aurora Carneiro Zen \\ Doutora em Administração pela Universidade Federal do Rio Grande do Sul - UFRGS \\ Professora da Universidade Federal do Rio Grande do Sul - UFRGS \\ E-mail: aurorazen@gmail.com (Brasil)
}

\section{Marlon Dalmoro}

Doutorando em Administração pela Universidade Federal do Rio Grande do Sul - UFRGS

E-mail: marlondalmoro@gmail.com (Brasil)

\section{Jaime Evaldo Fensterseifer}

Doutor em Ciências Administrativas pela University of California Los Angeles, Estados Unidos

Consultor da Coordenação de Aperfeiçoamento de Pessoal de Nível Superior

E-mail: jaime.ef@terra.com.br (Brasil)

\section{Douglas Wegner}

Doutor em Administração pela Universidade Federal do Rio Grande do Sul - UFRGS

Professor do Programa de Mestrado Profissional em Administração da Universidade de Santa Cruz do Sul - PMPA/UNISC

E-mail: douglaswegner@hotmail.com (Brasil) 
O Desenvolvimento de Recursos em Redes Interorganizacionais e o Processo de Internacionalização: O Caso Wines of Brasil

\title{
O DESENVOLVIMENTO DE RECURSOS EM REDES INTERORGANIZACIONAIS E O PROCESSO DE INTERNACIONALIZAÇÃO: O CASO WINES OF BRASIL
}

\section{RESUMO}

A internacionalização tem se tornando um imperativo para a sobrevivência de diversos setores industriais brasileiros. No caso do setor vinícola, o crescimento da concorrência com vinhos importados nos últimos anos tem levado as empresas do setor a buscarem novos mercados além das fronteiras nacionais. Nesse sentido, a articulação das empresas em redes interorganizacionais pode estimular o processo de internacionalização por meio da geração de recursos que extrapolam os limites das empresas. Este trabalho analisa o desenvolvimento de recursos no âmbito de uma rede interorganizacional do setor vinícola e a influência destes recursos no processo de internacionalização das empresas. Para tanto, realizou-se um estudo exploratório na Rede Wines of Brasil. Os resultados evidenciam que a rede tem colaborado para a geração de recursos, tais como a reputação do vinho brasileiro, o conhecimento do mercado e o fluxo de informação entre os participantes. Os recursos gerados na Rede e com acesso exclusivo aos membros deste grupo foram denominados de recursos de clube. Entretanto, a apropriação desses recursos não ocorre de maneira homogênea, evidenciando a existência de assimetrias entre seus membros, devido a arquiteturas organizacionais específicas dos membros da rede, tais como porte, base de recursos complementares e capacidade absortiva das empresas.

Palavras-chave: Internacionalização; Recursos; Redes de Empresas.

\section{THE DEVELOPMENTOF RESOURCES ININTERORGANIZATIONALNETWORKSAND THEINTERNATIONALIZATION PROCESS: THE CASE WINES OFBRASIL}

\begin{abstract}
The internationalization has become an imperative for survival of many Brazilian industrial sectors. In the wine industry, the growth of competition with imported wines in last years has led companies in the industry to seek new markets abroad. In this way, the formation of interorganizational networks could stimulate the internationalization process by generating collective resources. This paper analyzes the development of resources within a network of interorganizational wine industry and the influence of these resources in the process of internationalization of companies. Therefore, we carried out an exploratory study in a network called Wines of Brasil. The results show that the network has contributed to the generation of resources, such as the reputation of Brazilian wine, market knowledge and access to information among participants. The network' resources were denominate 'good club'. However, the appropriation of these resources does not occur homogeneously, showing the existence of asymmetries, due to specific organizational architectures of network members (i.e. size, resource base and absorptive capacity of complementary businesses).
\end{abstract}

Keywords: Internationalization; Resources; Interorganizational Networks. 


\section{DESARROLLO DE RECURSOS Y PROCESO INTERORGANIZACIONAL REDES INTERNACIONALIZACIÓN: EL CASO DE LOS VINOS DEL BRASIL}

\section{RESUMEN}

La internacionalización se ha convertido en un imperativo para la supervivencia de muchos sectores industriales brasileños. En el caso de la industria del vino, el crecimiento de la competencia con los vinos importados en los últimos años ha llevado a las empresas en la industria a buscar nuevos mercados más allá de las fronteras nacionales. En este sentido, la articulación de las empresas en redes interorganizacionales puede estimular el proceso de internacionalización mediante la generación de recursos que van más allá de los límites de las empresas. En este trabajo se analiza el desarrollo de los recursos dentro de una red entre organizaciones de la industria del vino y la influencia de estas características en el proceso de internacionalización. Por lo tanto, se realizó un estudio exploratorio Vinos de red de Brasil. Los resultados muestran que la red ha contribuido a la generación de recursos, tales como la reputación de los vinos de Brasil, el conocimiento del mercado y el flujo de información entre los participantes. Los fondos generados en la red y el acceso exclusivo a los miembros de este grupo fueron nombrados Club de recursos. Sin embargo, la apropiación de estos recursos no se produce homogéneamente, que muestra la existencia de asimetrías entre sus miembros, debido a las arquitecturas organizacionales específicas de los miembros de la red, como el tamaño, la base de recursos y la capacidad de absorción de los negocios complementarios.

Palabras-clave: Internacionalización; Recursos; Redes de Empresas. 


\section{INTRODUÇÃO}

A internacionalização é um desafio crescente para as empresas brasileiras, sobretudo em setores com elevada competitividade no mercado doméstico. Nesses setores a inserção no mercado internacional torna-se uma alternativa estratégica para obtenção de novos consumidores e de reconhecimento no mercado nacional. Este é o caso do setor vinícola, no qual se constata que o expressivo crescimento da concorrência com vinhos importados nos últimos anos, o que pressionado as empresas do setor a buscarem mercados além das fronteiras nacionais.

Diante desse desafio, a articulação das empresas em redes interorganizacionais pode estimular o processo de internacionalização por meio da geração de recursos necessários à inserção internacional. A dinâmica das relações interorganizacionais possibilita o desenvolvimento de recursos que extrapolam os limites das empresas e que poderão facilitar o processo de internacionalização. Diversos autores (e.g. Chetty \& Holm, 2000; Seppo, 2007) ressaltam que a associação em redes pode ajudar as empresas a obter conhecimentos, aprender com as experiências dos parceiros e se beneficiar com os efeitos da sinergia do rol de recursos, com influências positivas para o processo de internacionalização. Neste contexto, a Visão Baseada em Recursos (VBR) possibilita uma nova perspectiva de análise do processo de internacionalização e da influência das redes interorganizacionais.

Este artigo tem como objetivo analisar o desenvolvimento de recursos no âmbito das redes interorganizacionais e a influência destes no processo de internacionalização. Para tanto, desenvolveu-se um estudo de caso na WinesofBrasil, uma rede horizontal de vinícolas que visa estimular as exportações neste setor. Foram realizadas 16entrevistas semi-estruturadas com os gestores de empresas participantes da Rede e gestores executivos da rede.

Na sequência, apresenta-se uma revisão da literatura sobre o processo de internacionalização em redes interorganizacionais e o desenvolvimento de recursos para essa finalidade. A terceira parte do artigo trata dos procedimentos metodológicos adotados. A apresentação e a análise do caso serão abordadas na quarta parte. Por fim, as considerações finais trazem as implicações do trabalho, bem como as limitações e indicações para novas pesquisas. 


\section{OS RECURSOS EM REDES INTERORGANIZACIONAIS}

A Visão Baseada em Recursos (VBR) se desenvolveu principalmente a partir da década de 1980, ressaltando a importância da análise do ambiente interno da firma para o desenvolvimento de uma estratégia que possibilite a obtenção de vantagem competitiva sustentável no mercado. Nessa perspectiva, a firma é vista como uma coleção de recursos à disposição de uma unidade administrativa (Penrose, 1959) e estes recursos e capacidades são a base para a estratégia organizacional, constituindo a fonte primária de lucro para a firma (Grant, 1991).

De acordo com Barney (1991), as firmas obterão uma vantagem competitiva sustentável por meio de estratégias que as possibilitem explorar suas forças internas em resposta às oportunidades do ambiente, enquanto neutralizam as ameaças externas e suas fraquezas internas. Para que uma empresa obtenha uma vantagem competitiva sustentável deverá possuir recursos estratégicos e ser capaz de criar valor para o mercado com base nesses recursos. Entretanto, o valor estratégico dos recursos dependerá da combinação que a firma fará dos mesmos e da trajetória que a organização seguirá (Black e Boal, 1994), criando uma estratégia de criação de valor que não pode ser facilmente implementada pelos concorrentes atuais e potenciais.

Diversos autores apresentam as características dos recursos geradores de vantagem competitiva sustentável, denominados de recursos estratégicos. Grant (1991) argumenta que os recursos estratégicos da firma devem ser: duráveis, ou seja, não se tornarem obsoletos rapidamente; não transparentes, que significa de difícil imitação; não transferíveis e; não replicáveis por meio do desenvolvimento interno das firmas concorrentes. Já para Dierickx e Cool (1989), a vantagem competitiva sustentável é uma decorrência de recursos não disponíveis no mercado, não imitáveis e sem substitutos. Nesse mesmo sentido, Peteraf (1993) apresenta quatro macro-condicionantes para a obtenção de vantagem competitiva sustentável: heterogeneidade de recursos, limites ex-post para competição, mobilidade imperfeita de recursos e limites ex-ante para competição.

Na concepção de Barney (1991), para que os recursos de uma empresa possam gerar uma vantagem competitiva sustentável deverão atender a quatro requisitos: serem valiosos, no sentido de explorar as oportunidades do ambiente em que a firma se insere; serem raros entre as empresas concorrentes; serem de imitação imperfeita; e não possuírem substitutos estrategicamente equivalentes. Pode-se verificar que a heterogeneidade e a mobilidade imperfeita dos recursos são os dois pontos centrais para a obtenção de vantagem competitiva sustentável (Dierickx\&Cool, 1989; Barney, 1996; Grant, 1991; Peteraf, 1993). De acordo com Barney (1991), os mecanismos que possibilitam uma imitação imperfeita são: a dependência da trajetória histórica única da firma, a ambiguidade causal e a complexidade social. 
O Desenvolvimento de Recursos em Redes Interorganizacionais e o Processo de Internacionalização: O Caso Wines of Brasil

A dependência da trajetória significa que os recursos foram desenvolvidos no decorrer da história da organização e, portanto, não poderiam ser imitados pelos concorrentes, pois refletem o resultado de uma trajetória de circunstâncias únicas e de erros, acertos e aprendizagem.A ambiguidade causal ocorre quando as relações de causa e efeito entre os recursos da empresa e sua vantagem competitiva não são perfeitamente compreendidas, nem mesmo pela própria organização, dificultando a replicação de sua estratégia pelos concorrentes (Reed \&DeFillippi, 1990). As condições de ambiguidade causal indicam a impossibilidade da identificação dos recursos geradores da vantagem competitiva sustentável, impedindo que os concorrentes imitem a estratégia adotada pela empresa.Por fim, os recursos podem ser gerados a partir de fenômenos sociais complexos, que estão além da capacidade de influência e gestão da firma. A elevada complexidade social em que o recurso se forma reduz a habilidade de imitação das concorrentes. Um exemplo de recurso de elevada complexidade social é a cultura organizacional, que poderia gerar uma vantagem competitiva sustentável no mercado, porém de imitação imperfeita, pois se desenvolve a partir da interação dos atores sociais em um determinado contexto (Barney, 1991).

A Visão Baseada em Recursos (VBR), desenvolvida inicialmente para explicar a obtenção de vantagem competitiva sustentável no mercado, a partir dos recursos estratégicos das firmas (Wernerfelt, 1984; Barney, 1986, 1991; Dierickx\&Cool, 1989; Grant, 1991; Peteraf, 1993), poderá dar suporte à análise de arranjos interorganizacionais (e.g. redes de empresas e clusters industriais), nos quais relações de competição e cooperação ocorrem simultaneamente. Os recursos compartilhados gerados nas idiossincrasias das relações interorganizacionais poderão impactar no desempenho das organizações(Dyer\& Singh, 1998; Wilk\&Fensterseifer, 2003a; Neckelet al., 2010; Zen et al., 2011). A próxima seção aborda o desenvolvimento de recursos no contexto das relações interorganizacionais.

\subsection{CRIAÇÃO DE RECURSOS EM RELAÇÕES INTERORGANIZACIONAIS}

Se, por um lado, a VBR caracteriza-se pela análise dos recursos internos da empresa, diversos estudos (Wernerfelt, 1984; Barney, 1986, 1991; Dierickx\&Cool, 1989; Grant, 1991; Peteraf, 1993) apontam que as relações interorganizacionais podem contribuir para criação de recursos e geração de uma vantagem competitiva sustentável.

Nesse sentido, os recursos estratégicos podem ser expandidos para suas fronteiras da firma e gerados a partir de relações interorganizacionais (Dyer \& Singh, 1998). Surge assim a Visão Relacional, cuja a principal contribuição é ampliar a unidade de análise da firma, conforme 
preconizado pela VBR, para a rede de relacionamentos interorganizacionais da firma. Assim, se a firma não possui todos os recursos necessários para o desenvolvimento de uma vantagem competitiva, uma resposta possível é combinar seus recursos com aqueles de organizações externas através de diferentes arranjos cooperativos.

No âmbito das aglomentações geográficas, diversos autores (e.g.Molina-Morales, 2001, Wilk \& Fensterseifer, 2003a; Neckel et al., 2010; Zen et al., 2011) apontam ambiente gerado no cluster poderá influenciar na geração de recursos compartilhadosque afetam o desempenho das organizações de diversas formas. Sendo assim, o desenvolvimento de recursos acessíveis no cluster poderia, então, ampliar a competitividade das organizações presentes na aglomeração, facilitando a sua inserção no mercado internacional (Zen et al., 2011).

Das e Teng (2000) desenvolveram uma teoria da aliança estratégica baseada nos recursos, na qual observam o objetivo dos parceiros de obter acesso aos recursos de outras organizações, mais do que aplicar seus próprios recursos. Assim, as relações interorganizacionais também podem ser fontes de recursos estratégicos para as organizações, facilitando o acesso aos recursos necessários para o ingresso no mercado internacional.Wilk e Fensterseifer (2003b) complementam que as alianças interfirmas podem ser concebidas como estratégias de combinação e acesso a recursos, permitindo a redução de tempo e investimentos para a formação do portfólio de recursos necessário para adquirir e sustentar uma vantagem competitiva. No processo de internacionalização, as alianças possibilitam o acesso a recursos, que podem contribuir para a competitividade internacional da empresa.

Larentis e Slongo (2008) consideram que o relacionamento pode ser tratado como um recurso ou como uma conjugação de ativos, recursos e aptidões que permitem à empresa alcançar posições estratégicas diferenciadas. Na visão desses autores, a rede poderia ser um recurso, contudo, outros autores (e.g.Dyer, 1996; Chetty\&Agndal, 2007; Chetty\&Holm, 2006; Seppo, 2007) argumentam que as relações interorganizacionais podem ser geradoras de recursos e rendas, e consequentemente, de vantagem competitiva sustentável.

Cabe ressaltar que os recursos gerados nas relações interorganizacionais, tais como redes de empresas e alianças estratégicas, não terão o mesmo impacto na performance para todas as firmas participantes. Essas assimetrias podem estar relacionadas aos recursos singulares das firmas e aos níveis de apropriação dos recursos gerados pela rede em função das características das firmas e da capacidade absortiva de cada parceiro. Cohen e Levinthal (1990) definem capacidade absortiva como a capacidade de uma organização em reconhecer o valor de uma informação, assimilá-la e então poder utilizá-la com uma finalidade comercial. Esta capacidade pode estar relacionada à 
O Desenvolvimento de Recursos em Redes Interorganizacionais e o Processo de Internacionalização: O Caso Wines of Brasil

trajetória histórica da firma, ao conhecimento acumulado e aos seus processos de aprendizagem. Além disso, a complementariedade entre os recursos gerados pela rede e os recursos singulares da firma também poderá impactar em diferenças na apropriação e no desempenho dos membros da rede. Assim, os parceiros não absorvem os recursos da rede de maneira homogênea, fazendo com que algumas firmas não tenham capacidade para incorporá-los a sua estratégia de atuação.

Em suma, "a firma poderá acessar recursos através dos seus relacionamentos internos, ou ainda, por meio dos relacionamentos externos com outras firmas" (Chetty\&Agndal, 2007, p. 3). A principal proposição teórica deste trabalho é de que as redes interorganizacionais possibilitam o desenvolvimento de recursos, que por sua vez podem influenciar o processo de internacionalização das empresas participantes. A seguir, apresenta-se uma revisão do processo de internacionalização em redes de empresas.

\section{$\begin{array}{llllllll}2.2 & O & \text { PROCESSO DE } & \text { INTERNACIONALIZAÇÃO } & \text { E } & \text { AS } & \text { REDES }\end{array}$ INTERORGANIZACIONAIS}

O conceito de internacionalização de empresa pode ser descrito como um processo crescente de envolvimento de uma empresa no mercado de outros países fora de sua base de origem (Paivaet $a l, 2004)$. O processo de formação de uma estratégia de internacionalização se concretiza com a escolha do modo de ingresso no mercado estrangeiro, as quais variam em função do nível de comprometimento de recursos e da complexidade inerentes às operações internacionais (Honório \&Rodrigues, 2006). As modalidades de ingresso no mercado internacional compreendem desde as exportações ocasionais até o estabelecimento de subsidiárias de produção, ou mesmo de formas alternativas, como o licenciamento, as franquias, as joint-ventures e as alianças estratégicas (Czinkotaet al., 1996).

A internacionalização de uma empresa pode ser observada como um processo gradual ou uma decisão racional de expansão dos negócios para além das fronteiras nacionais. Na análise das principais teorias de internacionalização é possível fazer um agrupamento de duas abordagens principais. De um lado encontram-se os estudos de abordagem comportamental, baseado na escola nórdica - Modelo de Uppsala, o qual apresenta a internacionalização como uma consequência de uma sequência de estágios, seguindo um percurso sequencial em conexão com a experiência e o conhecimento dos mercados externos (Johanson \& Wiedersheim- Paul, 1975; Johanson \& Vahlne, 1977). De outro lado estão os trabalhos que se apoiam em uma abordagem econômica, proporcionada pela teoria dos Custos de Transação (Williamson, 1975), a partir da teoria de 
internalização e do paradigma eclético da produção (Dunning, 1988), na qual as empresas organizam suas atividades pelo mercado ou por hierarquia, buscando vantagens de localização, de propriedade e de internalização, bem como a maximização dos ganhos econômicos.

O Modelo de Uppsala tem sido muito difundido para explicar a internacionalização de pequenas e médias empresas, que, predominantemente, ampliam sua inserção de maneira gradual. Entretanto, cabe apontar importantes limitações do modelo, tais como a influência do indivíduo na percepção de distância psíquica e das redes de relacionamentos da empresa no processo de internacionalização. Com base nesse último aspecto, desenvolveu-se a teoria das redes ou networks, considerada uma evolução do Modelo de Uppsala, pois mantém alguns de seus pressupostos centrais, contudo enfatizando os relacionamentos existentes entre diferentes atores para a internacionalização.

Johanson e Mattsson (1988) argumentam que as redes de negócios são um elemento central no entendimento do processo de internacionalização. Estas são definidas como os relacionamentos que a firma estabelece com clientes, distribuidores, fornecedores, concorrentes e governo. Assim, o número e a intensidade dos relacionamentos entre as diferentes partes da rede aumentam em decorrência da internacionalização.

A Teoria de networks aponta que o contexto de negócios baseia-se, principalmente em relacionamentos específicos com outros atores, tornando possível um entendimento mais amplo dos fatores decisivos subjacentes ao processo de internacionalização da firma. Ademais, a teoria sugere que o grau de internacionalização de uma firma reflete não somente os recursos alocados no exterior, mas também o grau de internacionalização da rede em que ela está inserida (Hilal \& Hemais, 2003).

Uma outra corrente de autores também busca analisar o processo de internacionalização por meio de redes interorganizacionais, especialmente no contexto de pequenas e médias empresas. Entretanto, nessa perspectiva, as redes interorganizacionais poderiam prover um conjunto de recursos, gerando a partir da dinâmica da relação entre os parceiros, que influenciam a internacionalização das empresas. A decisão de internacionalização será direta ou indiretamente influenciada pelos demais membros da rede em que a empresa se insere (Meyer\& Skak, 2002; Seppo, 2007).

Chetty e Wilson (2003) argumentam que as redes de negócios permitem o acesso a diversos recursos necessários à estratégia de internacionalização da firma. Os achados do estudo realizado mostram que a habilidade das firmas para acessar recursos de outras organizações, principalmente por meio de redes horizontais, pode ser uma importante variável explicativa no engajamento 
O Desenvolvimento de Recursos em Redes Interorganizacionais e o Processo de Internacionalização: O Caso Wines of Brasil

internacional. Seppo (2007) aponta ainda que a habilidade de usar os recursos disponíveis nas redes interorganizacionais poderá acelerar o processo de internacionalização e também aumentar o sucesso deste processo no mercado internacional.

Assim, as redes podem oferecer um meio eficiente das firmas superarem suas deficiências de recursos e capacidades organizacionais. Os relacionamentos de longo prazoentre os parceiros da redepodem representar um benefício estratégico, pois possibilitam o acesso direto e indireto a recursos-chave, habilidades e conhecimentos controlados por outros membros da rede. As vantagens desses recursos poderão ser sustentáveis, uma vez que são de difícil imitação para organizações externas à rede (Lin\&Chaney, 2007).

Cabe ressaltar que o foco deste trabalho não é analisar a rede interorganizacional como modo de ingresso no mercado internacional, mas a influência da rede no processo de internacionalização por meio dos recursos desenvolvidos em decorrência desta relação. A seguir, apresenta-se o método de pesquisa utilizado para o desenvolvimento deste trabalho.

\section{MÉTODO}

A estratégia de pesquisa adotada neste trabalho é o estudo de caso. Diversas pesquisas sociais estão fundadas no estudo detalhado de casos particulares, ou seja, numa análise intensiva, empreendida numa única ou em algumas organizações reais. O estudo de caso não é apenas um método, mas a escolha de um objeto a ser estudado, examinando o fenômeno dentro de seu contexto (Yin, 2001). Na concepção de Creswell (1994), utiliza-se o estudo de caso quando o pesquisador quer explorar uma ou poucas entidades ou fenômenos, limitado pelo tempo e atividade (grupo social) e quer coletar informações usando uma variedade de procedimentos de coleta de dados durante um período de tempo. Para Mitchell (1983), os estudos de caso são uma forma de organizar dados sociais, preservando a característica unitária do objeto social a ser estudado.

No presente estudo, a unidade em análise é a Rede WinesofBrasil (WofB), sediada na cidade de Bento Gonçalves. No ano de 2008, a Rede era formada por 34 empresas, a Rede possui um papel chave no processo de internacionalização do setor vinícola brasileiro, correspondendo a cerca de $50 \%$ das exportações do setor (WofB, 2008). Destaca-se que o projeto possui as características de uma rede interorganizacional de caráter industrial, organizada na forma horizontal, que desenvolve atividades internacionais com as características de consórcio de exportação. A Rede selecionada foi 
definida no estudo como rede focal e os atores da rede são as empresas participantes e as instituições relacionadas ao setor.

A coleta dos dados ocorreu por meio de observação direta não-participanteem eventos da rede, entrevistas semi-estruturadas e documentos e relatórios estatísticos sobre o setor vitivinícola brasileiros. A coleta destas evidências ocorreu durante visitas in loco, realizadas nos meses de setembro e outubro de 2008. Para a coleta de dados primários foram realizadas entrevistas semiestruturadas com os gestores de 14 empresas participantes da rede, mais dois gestores executivos da Wines of Brasil e do Instituto Brasileiro do Vinho (IBRAVIN).

Foram desenvolvidos dois roteiros para condução das entrevistas. O primeiro roteiro, utilizado no IBRAVIN e Wof B, teve como objetivo identificar elementos relacionados ao histórico da rede, processo de formação, principais ações e mecanismos de gestão. O segundo roteiro, destinado às empresas, buscava analisar o processo de internacionalização (motivação, barreiras, estratégias adotadas) e a influência da rede nesse processo. Desse modo, foi possível identificar a trajetória de internacionalização das empresas, os recursos gerados no âmbito da rede e a relação entre esses dois elementos.

No tratamento dos dados, utilizou-se a técnica de análise de conteúdo. Para Bardin (1977), esta técnica visa, por meio de procedimentos sistemáticos e objetivos de descrição do conteúdo, a geração de indicadores que permitam a inferência de conhecimentos. A partir das transcrições das entrevistas, buscou-se identificar categorias relacionadas ao processo de internacionalização e ao desenvolvimento de recursos.

\section{WINES OF BRASIL: APRESENTAÇÃO E ANÁLISE DOS RESULTADOS}

O Brasil já se consolida como o quinto maior país produtor de vinhos em volume do hemisfério sul. Com uma produção de 3,2 milhões de hectolitros no ano de 2008, o Brasil só é superado pela Argentina (14,8 milhões de hectolitros), Austrália (10,3 milhões), África do Sul (8,9 milhões) e Chile (8,4 milhões) (Wof B, 2008). Entretanto, o consumo per capita no Brasil ainda é muito baixo. Conforme dados do Wine Institute (2010), o Brasil, no ano de 2008, estava na $101^{\circ}$ posição no raking mundial de consumo com apenas 1,81 litros de vinhos per capita ao ano.

$\mathrm{Na}$ última década, o mercado mundial vitivinícola passou por profundas transformações com o aumento da produção e dos países produtores, acompanhada de uma gradativa queda no consumo per capita. Essa situação tem tornado a competição cada vez mais acirrada. Assim, a busca por 
mercados externos tornou-se um imperativo para a sobrevivência das empresas devido à redução do mercado doméstico e ao aumento dos competidores.

Inserido neste contexto, o setor vitivinícola brasileiro intensificou sua preocupação com a internacionalização no início dos anos 2000, em decorrência do expressivo aumento da concorrência com produtos importados. Segundo Fensterseifer (2007), no estágio atual da indústria de vinhos no Brasil e dado os agressivos esforços de exportação dos já estabelecidos países produtores de vinho, ingressar no mercado internacional pode ser um imperativo para a sobrevivência das vinícolas no seu próprio mercado doméstico.

A configuração do mercado mundial do vinho evidencia a necessidade de uma cooperação entre os atores e a construção de arranjos interorganizacionais que viabilizem o processo de internacionalização das empresas de um determinado país. Assim, a formação de redes poderá possibilitar o desenvolvimento de recursos estratégicos neste processo. A seguir analisa-se o caso da Rede Wines of Brasil.

\subsection{A REDE WINES OF BRASIL}

A Rede Wines of Brasilteve início no ano de 2002, por iniciativa da Federação das Indústrias do Estado do Rio Grande do Sul (FIERGS) e apoio da Agência de Promoção de Exportações (APEX). A FIERGS buscou vinícolas da Serra Gaúcha para desenvolver um consórcio de exportação do setor vitivinícola. Inicialmente, seis vinícolas aderiram ao projeto. As vinícolas participaram de diversas reuniões, cursos de formação de preço e treinamentos para acessar o mercado internacional. Este consórcio viabilizou o desenvolvimento de conhecimentos sobre o mercado internacional, a articulação política e a participação em feiras e eventos internacionais necessários para o processo de internacionalização das vinícolas.

Em 2004, esta iniciativa passou a ser um "Projeto Setorial Integrado" (PSI) contando com a parceria da Agência Brasileira de Promoção de Exportações e Investimentos (APEX) focando a promoção de vinho brasileiro através de um acordo com o Instituto Brasileiro do Vinho (IBRAVIN). A assinatura do convênio com a APEX trouxe uma mudança significativa na Rede, pois não se tratava mais de um consórcio de exportação (Wof B, 2008); a partir deste convênio, as vinícolas participantes atuariam de maneira cooperativa para a promoção do vinho brasileiro no exterior.

Segundo a Gerente da Rede, essa mudança possibilitou um grande salto qualitativo e quantitativo. No ano de 2007, a Wines of Brasil já era composta por 28 vinícolas com 20 países de 
destino das exportações, respondendo por $57,7 \%$ da exportação brasileira, em contraste com $15,2 \%$ em 2002. Além disso, possibilitou a participação de vinícolas brasileiras em 14 feiras internacionais, gerando 4.200 contatos comerciais e um volume de negócio estimado em US\$ 3,5 milhões para o ano de 2008 (Wof B, 2008).

A Wines of Brasil busca inserir o vinho brasileiro no mercado global. Nesse sentido, o grande desafio é a consolidação de uma imagem do país como produtor de vinho, ainda desconhecido no mundo do vinho. As ações da Rede estão centradas em quatro pilares: feiras internacionais, degustações, Projeto Comprador e Projeto Imagem.

As vinícolas participantes da Rede contam com vários benefícios. Entre eles destacam-se o auxílio financeiro para participação nas atividades relativas à promoção comercial subsidiados com recursos da APEX, apoio da entidade gestora, o IBRAVIN, e suporte institucional e financeiro do SEBRAE, FIERGS e SEDAI em ações específicas. A Rede também proporciona a troca de experiências entre as empresas participantes, além do fortalecimento da marca Wines of Brasil. As vinícolas podem participar de ações como feiras internacionais, degustações, missões comerciais, seminários, workshops, Projeto Comprador e Projeto Imagem (Wof B, 2008).

Cabe ressaltar que a Rede não atua na comercialização e na logística de distribuição do produto. Cada vinícola é responsável pelos seus contatos comerciais e pela entrega do produto. Nas palavras da Gerente da Rede: “(...) a parte comercial não é nossa parte, a gente controla as estatísticas, como estão andando, mas a gente não interfere (...) [a gestão da Wine of Brasil] auxilia dando informações, a venda é tarefa do departamento comercial de cada empresa".

Em relação ao processo de logística de distribuição, um grande desafio para as empresas no processo de internacionalização, a gestão da Rede busca desenvolver parcerias com empresas de logística para a redução do custo de distribuição e envio de amostras dos produtos. Verificou-se também a formação de uma rede informal entre as vinícolas participantes para a redução dos custos logísticos para exportação, como por exemplo, o compartilhamento de contêineres.

Desta forma, trata-se de uma rede interorganizacional de vinícolas brasileiras, apoiada pelo governo e entidades representativas da indústria. A Wines of Brasil, enquanto rede de negócios, pode ser caracterizada como um grupo intencionalmente formado de pequenas e médias empresas, conforme proposto por Human e Provan (1997): são geograficamente próximas; operam dentro da mesma indústria, podendo partilhar insumos e resultados; empreendem interações diretas entre si para resultados empresariais.

Em relação à gestão da Rede, a partir de 2004, tornou-se independente da FIERGS, atuando de maneira autônoma. A sede da WinesofBrasilé na cidade de Bento Gonçalves, região serrana do 
O Desenvolvimento de Recursos em Redes Interorganizacionais e o Processo de Internacionalização: O Caso Wines of Brasil

estado do Rio Grande do Sul e onde concentra-se o principal cluster vitivinícola do Brasil, localizada no mesmo espaço físico do Instituto Brasileiro do Vinho (IBRAVIN). Os participantes se reúnem em assembléia, a principal instância decisória da Rede. A Wof B ainda possui uma Gerente de Promoção Comercial, um Gerente Administrativo Financeiro, um Coordenador de Capacitação e um Assessor Jurídico.

Por tratar-se de um PSI, a Wines of Brasil é aberta para todas as empresas do setor, contudo, o foco da Rede é o vinho fino ${ }^{1}$, o que inibe o ingresso de vinícolas de exportam exclusivamente vinho de mesa. Para atrair novas vinícolas para a Rede são realizadas diversas ações, como eventos, visitas e apresentações em entidades setoriais. As empresas associadas pagam uma mensalidade que varia de 200 a 450 dólares, de acordo com sua produção de vinhos finos. Segundo os gestores da Rede, a mensalidade é uma forma de manter o comprometimento dos membros e auxiliar na manutenção operacional da Rede. Além disso, as empresas participantes devem definir um representante da empresa na Rede, participar das ações de adequação e promoção comercial, bem como participar das reuniões do grupo, fornecer informações sempre que solicitadas e prestar contas das atividades que desenvolverem em relação à Wof B.

Na visão de um dos entrevistados, a cooperação entre as empresas do setor para a formação da imagem do vinho do país no exterior é fator crítico para o sucesso do processo de internacionalização do setor. As vinícolas brasileiras necessitam cooperar para vencer o obstáculo do desconhecimento do produto no exterior e para definir o posicionamento do vinho brasileiro no mercado internacional.

Ampliando a visão da necessidade de cooperação no setor vinícola para a competitividade no mercado, Sato e Ângelo (2007) destacam que para atingir altos padrões de qualidade, as vinícolas brasileiras sofrem algumas desvantagens frente aos países produtores, que possuem vantagens na especificidade de localização, como Argentina e Chile, por estarem em zonas de aptidão de clima e solo. Os custos para atingir a qualidade equivalente são provavelmente mais elevados no Brasil, o que exige das vinícolas brasileiras um gerenciamento estratégico mais elaborado e investimentos em tecnologia e parcerias.

Outro aspecto relevante no processo de internacionalização é o desenvolvimento de conhecimento do mercado internacional por meio de cursos, palestras e acesso a eventos internacionais. Este elemento é essencial, especialmente para as pequenas vinícolas, com recursos limitados para investir em capacitação e em treinamento. Além disso, a participação em feiras e eventos internacionais possibilita o acompanhamento das tendências mundiais no processo produtivo e no consumo. Segundo umas das entrevistadas, a atuação da empresa no mercado 
mundial pode estimular o crescimento da empresa e uma melhoria no seu padrão competitivo no mercado doméstico.

A troca de informações é outro elemento importante apontado pelos entrevistados. A participação nas reuniões, eventos e confraternizações possibilita a criação de um espaço propício à troca de informações e à criação de uma rede informal entre os atores. Nas palavras de um entrevistado: "a gente troca muitas informações, inclusive contratos, se precisa de um produto (...) e a empresa normalmente não tem esse produto, pode oferece [algum produto de] linhas diferentes, isso ocorre". Também ressalta-se que as vinícolas participantes possuem características bem distintas, algumas com mais experiência internacional, outras em fase inicial de busca de informações. Apesar dessas diferenças, observa-se que as vinícolas mais experientes repassam seus conhecimentos e auxiliam no desenvolvimento das novas vinícolas participantes da Rede, especialmente nos treinamentos e na troca informal de informações.

No caso em análise, observa-se a existência de interligações entre empresas, entidades de classe e órgãos governamentais. O quadro institucional formado por estes atores atuando de maneira colaborativa, passa a ter um papel importante no que tange ao desenvolvimento da rede e a sua contribuição para as empresas participantes em virtude das externalidades positivas geradas no espaço local de colaboração. Essas externalidades geram um conjunto de fatores intangíveis que permitem a criação e ampliação de vantagens competitivas das empresas envolvidas na rede.

Neste setor, a proximidade geográfica proporcionada pela concentração de empresas no cluster vitivinícola da Serra Gaúcha tem gerado externalidades positivas. Esta visão corrobora com o trabalho de Alievi e Fensterseifer (2005) e ganha importância pelo fato de o vinho ser um produto cuja qualidade é um fator estratégico para a reputação da empresa. A qualidade do vinho depende de um investimento em toda a cadeia produtiva, desde a escolha das variedades adequadas e de boa qualidade, a condução correta do vinhedo, os cuidados na colheita e nas operações de fermentação, bem como durante a maturação e o envelhecimento do vinho. Desta forma, ações de integração entre as diversas empresas do setor ao longo de toda a cadeia produtiva proporcionam a geração de benefícios para o setor como um todo.

Segundo o Gerente do IBRAVIN, a Wines of Brasil contribui para a geração de externalidades para o setor, visto que desenvolve o setor como um todo ao promover os vinhos brasileiros, tornando-os conhecidos no exterior. O entrevistado argumenta que a venda do vinho brasileiro no exterior é um indicador de qualidade, e, dessa forma, amplia a competitividade do vinho brasileiro frente aos produtos importados no mercado doméstico. 
O Desenvolvimento de Recursos em Redes Interorganizacionais e o Processo de Internacionalização: O Caso Wines of Brasil

$\mathrm{Na}$ concepção dos entrevistados, a Rede tem proporcionado vantagens para empresas de pequeno, médio e grande portes. No caso da Vinícola Miolo, uma das maiores empresas da rede, o gerente acredita que a empresa não conseguiria fazer mais de 50\% das atividades internacionais desenvolvidas atualmente se não existisse a rede. Da mesma forma, as empresas menores participantes da Wines of Brasil também obtêm vantagens competitivas, tanto pelo fato de apresentarem variedades diferentes, quanto pelo acesso ao knowhow das empresas maiores pertencentes à rede e que já possuem experiência exportadora. A Figura 1 apresenta um desenho das relações interorganizacionais e da influência dos recursos no processo de internacionalização.

Figura 1 - Desenho da Rede

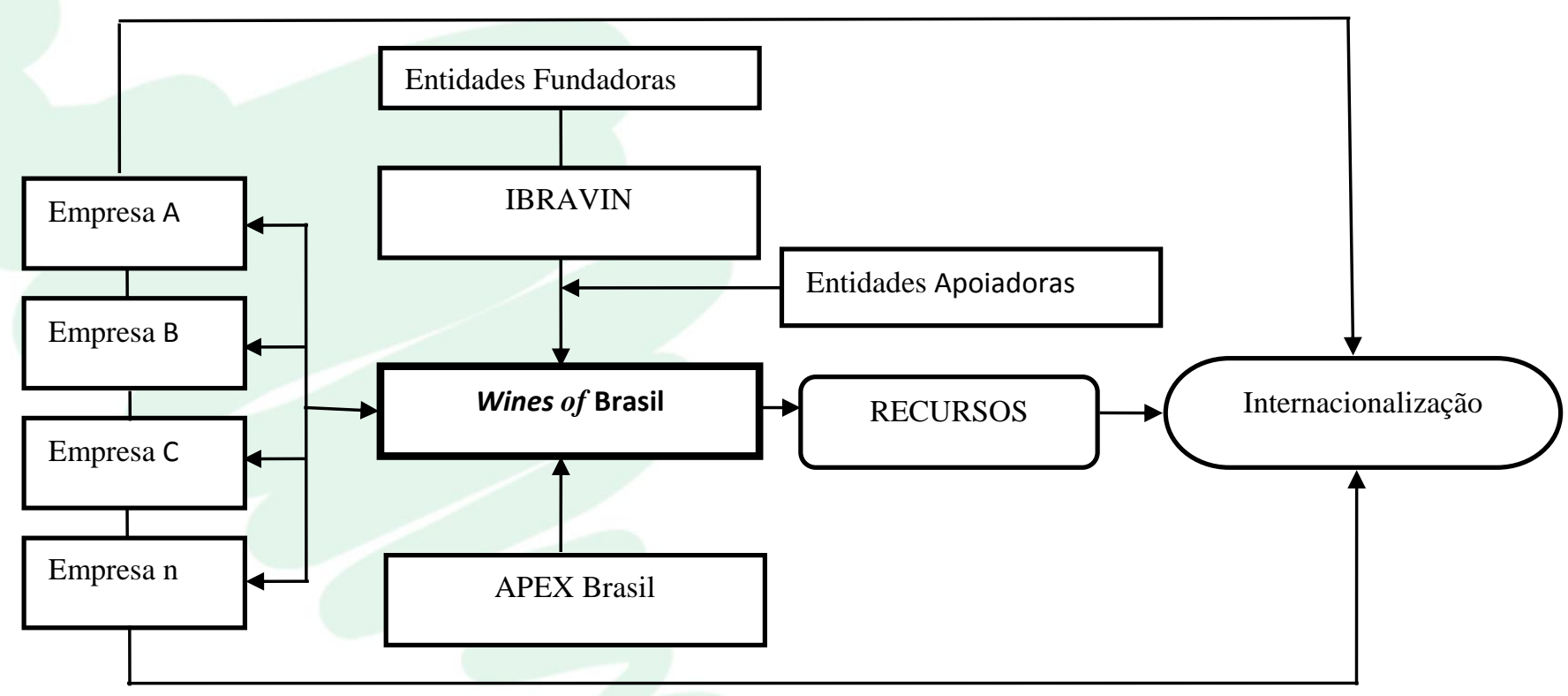

$\mathrm{Na}$ análise do caso identificou-se o desenvolvimento de três recursos intangíveis decorrente da Rede: a reputação do vinho brasileiro, o conhecimento do mercado internacional e o acesso a informações. No primeiro recurso - reputação do vinho brasileiro - as empresas participantes ou não da Rede poderão se beneficiar, entretanto, aquelas que desenvolvem atividades internacionais poderão desenvolver uma estratégia que explore esse recurso no mercado doméstico. Os entrevistados destacaram que a atuação no mercado internacional gera um status também mercado doméstico. Isso porque, segundo estes, a comercialização do produto no exterior altera a percepção do consumidor brasileiro em relação à qualidade do produto. No mercado de vinhos, esse recurso torna-se valioso, pois se trata de um elemento importante no processo decisório do consumidor. 
Para o gestor do IBRAVIN, a Wines of Brasil gera vantagens competitivas para as empresas por desenvolver o setor e promover o vinho brasileiro no mercado internacional, sinalizando qualidade também para o consumidor local. Assim, a internacionalização do vinho brasileiro também reflete na percepção do produto do consumidor no mercado doméstico. Essa mudança na percepção do consumidor também foi apontada pelos representantes das vinícolas entrevistadas.

$\mathrm{Na}$ visão das empresas associadas, a Rede contribui na geração de benefícios para o setor porque está disseminando uma ideia de qualidade e da possibilidade de expandir o mercado de atuação das vinícolas para além do Brasil. A representatividade proporcionada pelas ações em conjunto no mercado externo proporciona vantagens relativas para o setor, bem como para as empresas participantes, visto que no momento da associação em rede as empresas somam forças para a promoção do vinho brasileiro. A enóloga de uma das empresas destaca que se os compradores de vinho no mercador mundial souberem que o Brasil possui um produto bom, isso terá um impacto positivo para todos os membros da rede. Cabe ressaltar que esse impacto também será positivo para as demais empresas do setor vinícola brasileiro, não se limitando aos participantes da Rede.

Outro recurso intangível é o conhecimento sobre mercado internacional, pois as empresas têm acesso a eventos e treinamentos específicos para atuação no mercado internacional. Nesse aspecto, a base de conhecimento dos membros da rede é um elemento importante na geração desse recurso, uma vez que o suporte da rede depende do conhecimento e das experiências dos atores da rede (Seppo, 2007).

Também se verificou queo acesso à informação é um dos recursos gerados na rede que poderá influenciar a internacionalização das empresas. Nesse sentido, Seppo (2007) aponta que a obtenção de informações sobre o mercado como um dos impactos mais importantes das redes na internacionalização, uma vez que a falta de conhecimento é frequentemente uma limitação para o ingresso em mercados externos. O conhecimento e o aprendizado nas redes também poderão reduzir a incerteza do processo de internacionalização (Lin \& Chaney, 2007).

Por fim, cabe ressaltar que a Rede também poderá ter um efeito negativo no processo de internacionalização, uma vez que se trata de uma relação de interdependência, caso uma vinícola tenha um desempenho ruim em um determinado mercado, o ingresso de outras e a imagem do vinho brasileiro poderão estar comprometidos. Assim, fica evidente a importância do comprometimento das vinícolas no desenvolvimento das atividades internacionais, pois a má atuação de um ator afetará os demais no esforço de internacionalização. 
O Desenvolvimento de Recursos em Redes Interorganizacionais e o Processo de Internacionalização: O Caso Wines of Brasil

Seppo (2007) também aponta que as assimetrias de poder entre as empresas poderão ter um impacto negativo na Rede. Entretanto, este aspecto não foi apontado pelos entrevistados. Ao contrário, ressaltou-se que as diferenças entre as vinícolas têm um efeito positivo no acesso de informações e na base de conhecimento da Rede. A gerente da Rede destaca a preocupação em reduzir as assimetrias por meio de um processo de comunicação eficiente, no entanto observa que algumas empresas buscam mais informações junto ao projeto, podendo gerar um desequilibro no momento de utilizar as informações disponíveis. Assim, na Rede, as informações, conhecimentos e poder de decisão são compartilhados de maneira simétrica, no entanto a utilização destes mecanismos dentro da Rede é uma decisão interna a cada empresa, resultando em uma utilização dos recursos da Rede de maneira assimétrica entre as empresas.

\section{CONSIDERAÇÕES FINAIS}

Este trabalho teve como objetivo analisar o desenvolvimento de recursos no âmbito das redes interorganizacionais e a influência destes no processo de internacionalização. Para tanto, desenvolveu-se um estudo de caso na Wines of Brasil, uma rede horizontal de vinícolas brasileiras que visa fomentar as exportações neste setor.

A partir dos resultados obtidos é possível identificar que a Rede tem colaborado para o desenvolvimento de três recursos intangíveis: a reputação do vinho brasileiro, o conhecimento do mercado e o acesso à informação entre os participantes. A construção da reputação do vinho brasileiro poderá ter impacto tanto para o mercado externo como para o mercado interno, e beneficiar também empresas externas à Rede. Os relatos indicam que uma imagem positiva do vinho brasileiro, poderá aumentar a competitividade das vinícolas no mercado externo e no mercado doméstico. Os recursos conhecimento do mercado internacional e acesso à informação são compartilhados exclusivamente pelos membros da Rede. Esses recursos podem ser definidos como recursos de clube, ou seja, recursos desenvolvidos a partir da interação de um grupo de empresas e com acesso restrito aos participantes do grupo. Contudo, esses recursos poderão ter diferentes níveis de impacto na estratégia internacional das empresas, de acordo com as características organizacionais específicas e o nível de utilização dos mesmos.

Esses resultados do artigo corroboram com os achados de Lin e Chaney (2007) sobre os benefícios das redes interorganizacionais para o processo de internacionalização. Da mesma forma, Seppo (2007) aponta que a habilidade de usar os recursos disponíveis nas redes interorganizacionais 
poderá acelerar o processo de internacionalização e também aumentar o sucesso deste processo no mercado internacional.

O artigo traz como contribuições teóricas a aplicação da Visão Baseada em Recursos nas relações interorganizacionais e uma nova perspectiva das influências do processo de internacionalização. Como implicações gerenciais, os resultados deste trabalho indicam que os gestores de empresas em redes interorganizacionais poderão desenvolver uma estratégia de internacionalização considerando os recursos acessíveis no âmbito das redes, uma vez que os recursos de clube poderão ser fonte de vantagens competitivas para as empresas nesse processo. Além disso, a formulação de políticas públicas de apoio à internacionalização poderá considerar o fomento às redes interorganizacional como um mecanismo de apoio à competitividade internacional das empresas.

Cabe ressaltar que a apropriação dos recursos gerados pela Rede não ocorre de maneira homogênea, evidenciando a existência de assimetrias entre os membros da rede. Essas assimetrias resultam de arquiteturas organizacionais específicas (Tallmanet al., 2004) dos membros da rede, tais como porte, base de recursos complementares e capacidade absortiva. Novos trabalhos poderão investigar os fatores que influenciam a apropriação heterogênea dos recursos gerados nas redes interorganizacionais. Além disso, segundo Gellyncket al. (2007), as redes podem estimular o potencial de desenvolvimento da competência de inovação das firmas no contexto internacional. Sugere-se novas pesquisas para aprofundar a análise dessa relação.

\section{Nota}

1 A Lei n. 10.970, de 12 de novembro de 2004, estabelece classificação dos vinhos brasileiros quanto à classe como: a) de mesa; b) leve; c) fino; d) espumante; e) frisante; f) gaseificado; g) licoroso; h) composto. O vinho fino é o vinho de teor alcoólico de $8,6 \%$ a $14 \%$ em volume, elaborado mediante processos tecnológicos adequados que assegurem a otimização de suas características sensoriais e exclusivamente de variedades Vitis vinífera do grupo Nobres (BRASIL, 2009). 
O Desenvolvimento de Recursos em Redes Interorganizacionais e o Processo de Internacionalização: O Caso Wines of Brasil

\section{REFERÊNCIAS}

Alievi, R. M. ; Fensterseifer, J. E. O. (2005) Relações de cooperação e criação de vantagens competitivas: um estudo no arranjo vinícola da região da Serra Gaúcha - Brasil. In: Encontro da ANPAD, XXIX, Brasília, 2005. Anais... Rio de Janeiro: ANPAD.

Bardin, L.(1977) Análise de conteúdo.Lisboa: Edições 70.

Barney, J.B. (1991) Firm Resources and Sustained Competitive Advantage. Journal of Management, 17, 99-120.

Barney, J.B. (1996) Gaining and Sustaining Competitive Advantage. Reading-MA: AddisonWesley Publishing Company.

Black, J.A.; Boal, K.B. (1994) Strategic Resources: Traits, Configurations and Paths to Sustainable Competitive Advantage. Strategic Management Journal, 15.

Brasil. Lei Federal n. 10.970, de 24 de novembro de 2004. Disponível em <http://www.planalto.gov.br/ccivil/_Ato2004-2006/2004/Lei/L10.970.htm>. Acessoem 13 de abril de 2009.

Chetty, S. e Holm, D. B. (2000) Internationalization of small to medium-sized manufacturing firms: a network approach. International Business Review, 9, 77-93.

Chetty, S.; Agndal, H. (2007) Social Capital and Its Influence on Changes in Internationalization Mode Among Small and Medium-Sized Enterprises. Journal of International Marketing, 15(1), $1-29$.

Chetty, S.K.; Wilson, H.I.M. (2003) Collaborating with competitors to acquire resources. International Business Review, 12, $61-81$.

Cohen, W.M.; Levinthal, D.A. (1990) Absorptive Capacity: A New Perspective on Learning and Innovation. Administrative Science Quarterly, 35, 128 - 152.

Creswell, J. (1994) Research design: qualitative e quantitative approaches. Thousand Oaks: Sage.

Czinkota, M.R.; Ronkainen, I.A.; Moffett, M.H. (1996) International Business.Orlando: The Dryden Press.

Das, T. K.; Teng, B. S. (2000) A Resource-based theory of strategic alliances. Journal of Management, 26(1), 31-61. 
Dierickx, I.; Cool, K. (1989) Asset stock accumulation and the sustainability of competitive advantage. Management Science, 35(12), 1504-1511.

Dunning, J. H. (1988) The eclectic paradigm of international production: a restatement and some possible extensions. Journal of International Business Studies, 19(1), 1-31.

Dyer, J.H.; Singh, H. (1998) The Relational View: Cooperative Strategy and Sources of Interorganizational Competitive Advantage. Academy of Management Review, 23(4), 660 - 679.

Dyher, J.H. (1996) Specialized Supplier Networks as a Source of Competitive Advantage: evidence from auto industry. Strategic Management Journal, 17, 271 - 291.

Fensterseifer, J.E. (2007) The emerging Brazilian wine industry: challenges and prospects for the Serra Gaúcha wine cluster. International Journal of Wine Business Research, 19(3).

Gellynck, X.; Vermeire, B.; Viaene, J. (2007) Innovation in food firms: contribution of regional networks within the international business context. Entrepreneurship \& Regional Development, 19(3), 209-226.

Grant, R.M. (1991) The resource-based theory of competitive advantage. California Management Review, 33(3), 114-135.

Hilal, A.; Hemais, C.A. (Jan/Mar 2003) O processo de internacionalização na ótica da escola nórdica: evidências empíricas em empresas brasileiras. Revista de Administração Contemporânea, 7(1).

Honorio, L.; Rodrigues, S.B. (2006) Aspectos Motivacionais e Estratégicos na Internacionalização das Empresas Brasileiras. Revista de Administração Contemporânea, 46, 86 -98.

Human, S.E. e Provan, K.G. (1997) An emergent theory of structure and outcomes in small-firm strategic manufacturing network. Academy of Management Journal, 40(2), 368-403.

Johanson, J.; Mattsson, L. (1988) Internationalization in industrial systems: a network approach. In: Hood, H.; Vahlne, J. (Eds.). Strategies in foreign competition. London: Croom Helm.

Johanson, J.; Vahlne, J-E. (1977) The internationalization process of the firm: a model of knowledge development and increasing foreign market commitments. Journal of International Business Studies, 8(1), 23-32.

Johanson, J.; Wiedersheim-Paul, F. (1975) The internationalization of the firm: four Swedish cases. Journal of Management Studies, 10, 305-322. 
O Desenvolvimento de Recursos em Redes Interorganizacionais e o Processo de Internacionalização: O Caso Wines of Brasil

Larentis, F.; Slongo, L.A. (jul./ago./set. 2008) Relacionamento em canais de marketing como fonte de vantagem competitiva: um estudo com fabricantes de móveis e lojas exclusivas. R.Adm., São Paulo, 43(3), $209-223$.

Lin, K.; Chaney, I. (Oct. 2007) The Influence of Domestic Interfirm Networks on the Internationalization Process of Taiwanese SMEs. Asia Pacific Business Review, 13(4), 565-583.

Lorga, S. (2002) A internacionalização e os mecanismos de cooperação em redes na Vitrocristal ACE. Workpaper 02-002. Faculdade de Economia e Gestão. UniversidadeCatólica Portuguesa.

Mitchell, J.C.(1983) Case and situation analysis.The Sociological Review, 33, 187-211.

Molina-Morales, F.X. (2001) European industrial districts: Influence of geographic concentration on performance of the firm, Journal of International Management, 7, 277-294.

Neckel, A.R.; Hoffmann, V.E.; Schoreder, L. (2010) Recursos Compartilhados como Fonte Competitiva em Empresas Aglomeradas Territorialmente: um Estudo na Indústria Têxtil da Região de Rio do Sul (SC). Revista Ibero-Americana de Estratégia - RIAE, São Paulo, 9(1), 127 151.

OIV - Informações sobre a conjuntura mundial, março 2007. Disponível em: 〈http://www.oiv.int〉. Acesso em 10 mar. 2007.

Paiva, E.L.; Carvalho J.R.; Fensterseifer, J. E. (2004) Estratégia de produção e de operações. Porto Alegre: Bookman.

Pedersen, K. (Jan. 2002) The eclectic paradigm: 25 years anniversary. San Francisco: First International Business and Economy Conference.

Penrose, E. (1997) The theory of the growth of the firm, 1959. In: FOSS, N. J (Eds.). Resources, firms and strategies. New York: Oxford University Press.

Peteraf, M. A. (1993) The cornerstones of competitive advantage: a resource based-view. Strategic Management Journal, 14, 179-191.

Reed, R.; Defillippi, R.J. (1990) Causal Ambiguity, Barriers to Imitation and Sustainable Competitive Advantage.Academyof Management Review, 15(1), 88 - 102.

Sato, G. S.; Ângelo. J. A. (2007) Exportações de vinhos e derivados e o processo de internacionalização das vinícolas brasileiras. InformaçõesEconômicas,37(11). 
Seppo, Marge. (2007) The role of business networks in the internationalization of Estonian chemical industry enterprises. Tartu: Tartu University Press.

Tallman, S.; Jenkins, M.; Henry, N.; Pinch, S. (2004) Knowledge, clusters, and competitive advantage. Academy of Management Review, 29(2), 258-271.

Teece, D.J.; Pisano, G.; Shuen, A. (1997) Dynamic Capabilities and Strategic Management.Strategic Management Journal, 18(7).

Wernerfelt, B. (1984) A resource-based view of the firm. Strategic Management Journal, 5(2), 171-180.

WFB - WinesfromBrazil. Sobre o projeto. Disponível em:

http://www.winesfrombrazil.com.br.Acesso em: 10 out 2008.

Wiliamson, O. (1975) Markets and hierarchies: analysis and antitrust implications. New York: The Free Press.

Wilk, E.O.; Fensterseifer, J.E. (2003a) Use the Resourced-based View in Industrial Cluster Strategic Analysis. InternationalJournalofOperations\& Production Management, 23 (9); 995 1009.

Wilk, E.O; Fensterseifer, J.E. (2003b) J.E. Alianças Estratégicas sob a Perspectiva da Visão da Firma Baseada em Recursos: Contribuições para um Modelo Dinâmico de Cooperação. In: Encontro da ANPAD, XXXIX, Atibaia, 2003. Anais... Atibaia: ANPAD.

Yin, R. (2001) Estudo de caso: planejamento e métodos. 2. ed. Porto Alegre: Bookman.

Zen, A.C.; Fensterseifer, J.E.; Prévot, F. (2011) Internationalization of Clustered Companies and the Influence of Resources: A Case Study on Wine Clusters in Brazil and France. Latin American Business Review (Binghamton, N.Y.), 12, 123-141. 
O Desenvolvimento de Recursos em Redes Interorganizacionais e o Processo de Internacionalização: O Caso Wines of Brasil

Recebido: 29/12/2012

Aprovado: 13/02/2013 